\title{
Investigation of a temporal cluster of left sided congenital heart disease
}

\author{
NIGEL PANETH, ${ }^{23}{ }^{2}$ MICHELE KIELY, ${ }^{25}$ THOMAS HEGYI, ${ }^{7}$ AND I MARK \\ HIATT $^{6}$ ?
}

From The Sergievsky Center, ${ }^{1}$ Division of Epidemiology, ${ }^{2}$ and Department of Pediatrics, ${ }^{3}$ Columbia University, the New York State Psychiatric Institute, ${ }^{4}$ The New York State Institute for Basic Research in Developmental Disabilities, ${ }^{5}$ The Newborn Center, Monmouth Medical Center, ${ }^{6}$ and the Department of Pediatrics, The University of Medicine and Dentistry of New Jersey-Rutgers Medical School ${ }^{7}$

SUMMARY During October and November 1977, eight newborns with critical congenital heart disease, six of these with left sided lesions, were admitted to a New Jersey newborn unit serving two predominantly rural counties with 9700 annual live births. The six left heart lesions (three cases of hypoplastic left heart, two of interrupted aortic arch, and one of aortic coarctation) represented $30 \%$ of all neonatal left sided lesions seen at the unit in the three year period 1976-8. The scarr statistic for temporal clustering was significant $(p<0.05)$. A case-control study was performed inf which an average of four controls were matched to each case. A questionnaire was administered to 0 the mothers of cases and controls concerning occupation, periconceptional and prenatal nutrition radiation and chemical exposure, use of alcohol and tobacco, medications, immunisations infections, and other exposures. No statistically significant differences between cases and controls were found on any of these items. Although no aetiology for this cluster of congenital heark anomalies could be found, it is of interest that three temporal clusters of fetuses or newborns with chromosomal trisomies have been reported in the medical literature whose conceptions were roughly contemporaneous with those of the infants in our series. These occurred in Rhod $\varepsilon$ Island/Massachusetts, Maryland, and New York City. A speculative possibility is that these four point epidemics represented exposure to a common teratogenic agent, perhaps influenza $B$, in the winter of $1976 / 77$ in the northeastern United States.

The clustering of congenital malformations in time or in space can sometimes provide important clues to the cause of the malformation. Gregg first noted temporal clustering of congenital cataract and then further observed that the increase in incidence had been preceded by a rubella epidemic. ${ }^{1}$ Similarly, sudden increases in the incidence of vaginal adenocarcinoma and congenital phocomelia led to the discovery of two potent prenatal mutagens: diethylstilboestrol and thalidomide. ${ }^{23}$

Between 2 October 1977 and 17 November 1977, six newborns with left sided heart lesions, and two newborns with other critical heart disease, were admitted to Monmouth Medical Center, a regional intensive care nursery serving a two county area of south-central New Jersey. The specific diagnoses of these eight cases are given in table 1 . Of the six cases with lesions of the left side of the heart, five belonged to the hypoplastic left heart syndrome complex, of which two had interrupted aortic arch with ventricular septal defect. The sixth infant had infantile aortic coarctation. A review of the incidence of critical congenital heart disease among newborns at Monmouth Medical Center between 1976 and 1978 revealed an apparent clustering of left heart lesions during this period. The places of residence of the infants were widely spread throughout the two countries; there was thus no evidence of geographic clustering within the region.

In this study we report more detailed investigations of this cluster, including the results of a case-control study examining possible aetiologic factors. 
Table 1 Cases of congenital heart disease in Monmouth and Ocean Counties, New Jersey, in October-November 1977

\begin{tabular}{|c|c|c|c|}
\hline Date of birth & Sex & Diagnosis & Source of diagnosis \\
\hline 2 Oct. 1977 & $\mathbf{M}$ & Pulmonary atresia & Cardiac catheterisation \\
\hline 7 Oct. 1977 & $\mathbf{F}$ & Coarctation of aorta & Cardiac catheterisation \\
\hline 9 Oct. 1977 & $\mathbf{M}$ & $\begin{array}{l}\text { Hypoplastic left ventricle, } \\
\text { hypoplasia of preductal aorta }\end{array}$ & $\begin{array}{l}\text { Cardiac catheterisation } \\
\text { and necropsy }\end{array}$ \\
\hline 9 Oct. 1977 & $\mathbf{M}$ & $\begin{array}{l}\text { Anomalous pulmonary venous } \\
\text { return with drainage to the } \\
\text { inferior vena cava }\end{array}$ & Cardiac catheterisation \\
\hline 12 Oct. 1977 & $\mathbf{M}$ & $\begin{array}{l}\text { Ventricular septal defect with } \\
\text { interrupted aortic arch and } \\
\text { patent ductus arteriosus }\end{array}$ & Necropsy \\
\hline 20 Oct. 1977 & $\mathbf{F}$ & $\begin{array}{l}\text { Mitral atresia, aortic hypoplasia, } \\
\text { agenesis of left ventricle }\end{array}$ & Necropsy \\
\hline 27 Oct. 1977 & $\mathrm{~F}$ & Hypoplastic left ventricle & Necropsy \\
\hline 17 Nov. 1977 & $\mathbf{M}$ & $\begin{array}{l}\text { Ventricular septal defect with } \\
\text { interrupted aortic arch }\end{array}$ & $\begin{array}{l}\text { Cardiac catheterisation } \\
\text { and necropsy }\end{array}$ \\
\hline
\end{tabular}

\section{Methods}

TEMPORAL CLUSTERING

To test whether the apparent temporal clustering of cases could have occurred by chance we used the scan statistic. $^{4-6}$

This statistic uses the following notation:

$\mathrm{T}=$ total time interval under consideration

$\mathrm{t}=$ proposed duration of the epidemic

$\mathrm{r}=\mathrm{t} / \mathrm{T}$

$\mathrm{N}=$ total number of cases in time $\mathrm{T}$

$\mathrm{n}=$ total number of cases in time $\mathrm{t}$

The scan statistic is computed by taking a "moving window" of length $t$ and finding the maximum number of observations revealed through the window as it scans or slides over the entire time period $T$. The probability $p=P(n, N, r)$ that a maximum number of observations in any interval of length $\mathbf{t}$ exceeds or is equal to $\mathrm{n}$ under the hypothesis that $\mathbf{N}$ events are randomly distributed over the interval $T$ can be calculated, although the computational effort can be prohibitive. However, reference tables have been provided by Naus and Wallenstein. ${ }^{56}$

An advantage of this test is that it is not based on arbitrary calendar months but on the hypothesised duration of the epidemic. The proposed duration of $t$ must be decided before the data analysis.

\section{THE CASE-CONTROL STUDY}

In an attempt to investigate associations of possible causal importance, we matched several controls to each case and administered a questionnaire to the parents of cases and controls. One group of controls consisted of healthy newborns; an additional group of controls was composed of infants who had been admitted to newborn intensive care. Controls were matched according to the following protocol. The nearest birth in time noted on the log book of the hospital of delivery of the case was chosen, matched by date of LMP ( \pm 1 week), race, sex, and payment status (self pay or private insured $v$ Medicaid supported). All cases and controls were singletons. For the purpose of the case-control study, all infants admitted to Monmouth Medical Center in October and November 1977 with the diagnosis of critical congenital heart disease were considered to be cases.

The case-control was initiated approximately a year after the birth of the cases, and thus difficulty was encountered in obtaining completed interviews. The parents of two cases refused interview. In both instances the parents indicated that remembering the event was too painful and they did not wish to submit to interview. After initial contact no further attempts were made to interview these families in the study. Two families had moved from the area, one to California and another to West Germany. Both of these mothers returned questionnaires by mail, whereas the four other cases, and all participating controls, were personally interviewed. We aimed to obtain up to four "healthy" and two "sick" controls for each case. For the six interviewed cases, a total of 26 controls were interviewed. As the number of "sick controls" was small, all matched controls were considered together in the analysis. Data from 10 additional controls of uninterviewed cases were deleted from the study. The questionnaire used in this study was constructed from instruments used by Kline $^{7}$ and Oakley $^{8}$ in studies of spontaneous abortions and congenital anomalies respectively.

Analysis of the relation between exposures and outcomes followed the procedure suggested by Breslow and Day for a matched case-control study with a variable matching ratio and dichotomous exposure. ${ }^{9}$ We use the odds ratio as the measure of the association between exposure and disease in this study. For rare diseases this ratio closely approximates the relative risk of the disease occurring if the exposure is present as compared to when the exposure is absent. We first calculated odds ratios for all exposures of interest using the Mantel-Haenszel procedure. ${ }^{10}$ If the odds ratio was less than one, the variable was excluded from further analysis. If the odds ratio was greater than one, a more exact odds ratio was calculated using the conditional maximum likelihood estimate method. $95 \%$ confidence intervals and $\chi^{2}$ values for these odds ratios were then calculated. ${ }^{9}$ 


\section{Results}

TEMPORAL CLUSTERING

The number of cases of left sided heart lesions and other critical congenital heart disease admitted to Monmouth Medical Center between 1976 and 1978 is presented in the figure. The apparent excess of left sided heart lesions in October-November 1977 can be seen.

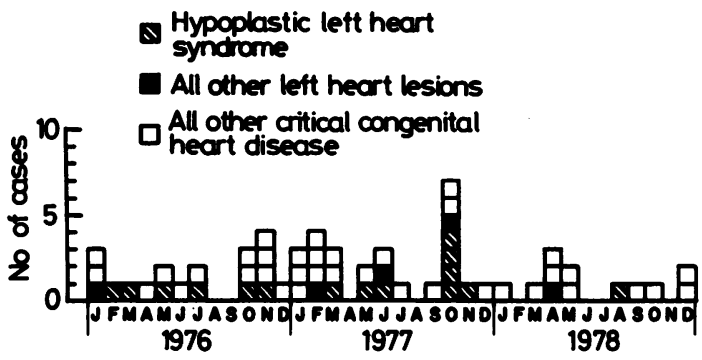

Incidence of critical congenital heart disease, Monmouth Medical Center, 1976-8

Of the 20 neonates witn left sided congenital heart lesions admitted to Monmouth Medical Center in the three year period, six (30\%) were born in the six week span, 7 October to 17 November 1977. The month of October 1977, in which five cases were admitted, was the only month in the three year period in which more than two infants with left sided congenital heart disease were seen. The 14 other cases were admitted over a period of 34 months, or a rate of 0.4 cases per month. Thus the expected number of cases in any two month period, based on the incidence experienced outside the epidemic period, was less than one seventh the observed figure.

The scan statistic for temporal clustering was applied to all critical congenital heart disease (CCHD) and to left sided lesions only. Using the tables provided by Wallenstein, ${ }^{6}$ the probability that eight or more cases of CCHD would be seen in two months when 57 were seen in three years is 0.65 . Thus CCHD overall did not tend to cluster. The probability that six or more cases of left sided congenital heart disease would be seen in two months when 20 were seen in three years is 0.046 . Thus left heart lesions occurred closer to one another in time significantly more often than would be expected by chance.

CASE-CONTROL STUDY

Several pregnancy exposures were found to be no more frequently reported among cases than among controls. These included the presence of pets in the home, respiratory or urinary infections, rashes, illnesses among family members, exposure of diagnostic $x$ rays, use of vaginal deodorants, and exposure to plastic Christmas trees. For exposures with odds ratios greater than one, the maximum likelihood estimate of the odds ratio and the $95 \%$ confidence limits around each of the odds ratios are presented in table 2. Although the odds ratios ranged from 1.47 to 8.02 , the lower bounds of all odds ratios were less than one, and none of the chi square statistics for association between the exposure and congenital heart disease was significant. It should be noted that the statistical power of this study was severely limited due to the small number of cases. The result that came closest to being significant was exposure to coffee in pregnancy, where the $\chi^{2}$ was $2 \cdot 48(0.05<\mathrm{p}<0 \cdot 10)$.

Table 2 Results of the case-control analysis

\begin{tabular}{|c|c|}
\hline Pregnancy exposure variable & $\begin{array}{l}\text { Maximum likelihood estimate ofodds ratio } \\
\text { (95\% confidence limit) }\end{array}$ \\
\hline Pesticides & $\begin{array}{r}1.90 \\
(0.33-11.00)\end{array}$ \\
\hline Cleaning fluids & $\begin{array}{r}1.49 \\
(0 \cdot 24-9 \cdot 00)\end{array}$ \\
\hline Paint/Paint remover & $\begin{array}{r}1.64 \\
(0 \cdot 26-10 \cdot 36)\end{array}$ \\
\hline Swine flu vaccine & $\begin{array}{r}3 \cdot 16 \\
(0 \cdot 18-54 \cdot 39)\end{array}$ \\
\hline Industrial plants in neighbourhood & $\begin{array}{r}7.02 \\
(0.64-76 \cdot 95)\end{array}$ \\
\hline Coffee & $\begin{array}{r}8 \cdot 02 \\
(0 \cdot 84-76 \cdot 87)\end{array}$ \\
\hline Cola & $\begin{array}{c}1.97 \\
(0.28-14 \cdot 08)\end{array}$ \\
\hline Smoking & $\begin{array}{r}1 \cdot 72 \\
(0 \cdot 31-9 \cdot 59)\end{array}$ \\
\hline Alcohol & $\begin{array}{r}5 \cdot 51 \\
(0 \cdot 20-150 \cdot 34)\end{array}$ \\
\hline Medication & $\begin{array}{r}3.45 \\
(0.12-102.97)\end{array}$ \\
\hline
\end{tabular}

\section{Discussion}

Five of the six left sided lesions described in this study can be considered part of the malformation complex described as the hypoplastic left heart syndrome (HLHS). In the expanded definition of HLHS of Noonan and Nadas, interruption and hypoplasia of the aortic arch are included. ${ }^{11}$ Although for the 
purpose of the case-control study all eight infants with critical congenital heart disease seen in the epidemic period were counted as cases, the striking feature of the cluster was the increased incidence of infants with lesions of the left side of the heart.

A comparison of the incidence of lethal left sided cardiac lesions in this study with vital statistics data from several sources confirms that the number of cases seen in the six week epidemic period was considerably in excess of expectation. In the eighth revision of the International Classification of Diseases, ${ }^{12}$ the left sided lesions described in this paper would be classified under one of the four following rubrics:

$\begin{array}{ll}746 \cdot 6 & \text { anomalies of heart valves } \\ 747 \cdot 1 & \text { coarctation of aorta } \\ 747 \cdot 2 & \text { other anomalies of aorta } \\ 746 \cdot 8 & \begin{array}{l}\text { other specified anomalies of heart } \\ \text { (including "hypoplasia, heart") }\end{array}\end{array}$

In New York City in 1976-7, 39 neonatal deaths were coded in these four categories for a prevalence at birth of $17 \cdot 7 / 100000 .{ }^{1}$ In New Jersey between 1975 and 1977,71 cases were seen for a rate of $23 \cdot 6 / 100000$ live births. ${ }^{14}$

These figures are compatible with data from large, well studied series of infants with congenital heart disease. In Blackpool, England from 1957 to 1971, where the neonatal necropsy rate was $93 \%$, a prevalence of 19.0/100 000 live births was found for HLHS. ${ }^{15}$ In Uppsala and Umea, Sweden, from 1961 to 1971 , among 279601 births, 97 infant deaths were attributed to mitral or aortic atresia and 14 to coarctation of the aorta, for a rate of $39 \cdot 7 / 100000$ live births. ${ }^{16}$ This rate is very similar to that found for deaths due to HLHS and coarctation in the 1958 British perinatal mortality survey of $34 \cdot 5 / 100000$ live births. ${ }^{17}$

The two predominantly rural New Jersey counties of Monmouth and Ocean are the referral base for Monmouth Medical Center. In 1977, these counties had 9700 live births. Thus for the months of October and November 1977, the prevalence at birth of HLHS and coarctation was $371 \cdot 1 / 100000$, or from 10 to 20 times the expected.

Investigations of point epidemics frequently make use of the comparisons of interview data on exposures in cases and suitably selected controls. This approach has been used successfully to pinpoint the source of acute infectious disease epidemics as far back as John Snow's investigations of cholera in London in the $1850 \mathrm{~s}^{18}$ Unfortunately, our investigation reveals some of the pitfalls of its use in the investigation of point epidemics of congenital malformations. The most serious limitation is that the number of cases available is usually small. The statistical power of the investigation can be increased by use of several individually matched controls. However, most statistical authorities agree that little increase in power is achieved by the use of more than four controls for each case. ${ }^{19}$ Thus, in this study, with 26 controls for six cases, about as much power as could be achieved through the size of the control population was achieved. A study such as ours would probably detect only a striking association, an exposure that is very frequent in cases and rarely found in controls. This was the case in the study of vaginal adenocarcinoma by Herbst $e t$ al ; among eight cases, all but one had been exposed prenatally to diethyl stilboestrol whereas among 32 controls, none had been so exposed. ${ }^{2}$

An unanticipated difficulty was our finding that two cases, $25 \%$ of the sample, refused to be interviewed, even though in both cases the request was made by the physician who cared for the infant. This observation emphasises the emotional trauma experienced by the parents of infants who die in the neonatal period. Investigations involving surviving infants are likely to be more successful in obtaining information based on maternal recall.

A number of studies have shown evidence of seasonal clustering in congenital heart disease. Of interest, in the light of the timing of the cluster we report here, is the fact that these studies have often found an autumn or late summer peak. Miettinen et al described a September-November peak in incidence for males with isolated preductal coarctation of the aorta among births in New England in the $1950 \mathrm{~s}^{20} \mathrm{~A}$ peak incidence in the same months was noted by Elwood for all congenital heart disease in selected Canadian provinces in the late 1960 s, but the excess did not achieve statistical significance. ${ }^{21}$ Rothman, who examined complex ventricular septal defect, found a significant August peak. ${ }^{22}$

Seasonal clustering of anomalies has often been viewed as supporting an infectious aetiology. Thus the temporal concurrence of this point epidemic with other malformation outbreaks is worthy of note. As we have previously reported, ${ }^{23}$ three clusters of anomalies have been described in the medical literature in which the affected fetuses or infants were conceived roughly contemporaneously with the infants in our series. One of these studies observed an increase in trisomies among spontaneous abortions in New York. ${ }^{24}$ The two other reports described increases in the prevalence of trisomy 13 in Massachusetts, ${ }^{25}$ and of trisomy 18 on the Rhode Island/Massachusetts border. ${ }^{26}$ Although simultaneous clusters of congenital anomalies are sometimes reported, the temporal coincidence of four reports from one section of a country is unusual. In the three other published reports, the 
malformation was chromosomal; in our study severe cardiovascular malformation was the finding. However, congenital heart disease is found in $90 \%$ of infants with trisomy 13 or $18 .^{27}$

If these four outbreaks were linked by a common mutagenic agent, a reasonable candidate would be a virus active in the late winter of 1976/7. The infants in our cluster were conceived in January or February 1977 , months which constituted the peak of influenza $B$ activity in the United States that winter. ${ }^{28}$ Influenza A activity peaked in late March. Moreover, influenza B was particularly active in the northeastern states in early 1977. The first isolations of the season were reported from New York City, New York State, New Jersey, Tennessee, and Texas. ${ }^{29}$ The only state reported by the Centers for Disease Control to have a "widespread" outbreak of influenza B in 1976/7 was New Jersey, a conclusion based on influenza B activity in late January $1977 .^{30}$

Evidence for a role of influenza virus in the aetiology of congenital malformation has been published. ${ }^{31} 32$ In our study, questioning of the mothers of cases and controls did not reveal an excess of respiratory illness during pregnancy in the mothers of cases. However, Hardy et al found that serological evidence of influenza infection during pregnancy was frequently found in the absence of symptoms and that rates of adverse pregnancy outcomes were raised in such asymptomatic mothers. ${ }^{32}$ The simultaneous clustering of several anomalies, and the seasonal clustering of cardiovascular anomalies, both point to a potentially infectious aetiology. This evidence, and the model provided by the teratogenic behaviour of the rubella virus, suggest that further investigation of the possibly infectious aetiology of congenital heart disease is warranted.

This study was supported in part by administrative grant \#6-210 from the National Foundation-March of Dimes. We thank the parents interviewed in this study for their participation, Godfrey Oakley, MD, Jennie Kline, PhD, and Sylvan Wallenstein, $\mathrm{PhD}$ for their advice, and interviewers Marsha Wolf and Janet Silverstein.

\section{References}

${ }^{1}$ Gregg NM. Congenital cataract following German measles in the mother. Trans Opthalm Soc Aust 1941; 3: 35-46.

${ }^{2}$ Herbst AL, Ulfelder H, Poskanzer DC. Adenocarcinoma of the vagina. Association of maternal stilbestrol therapy with tumour appearance in young women. New Eng Jnl Med 1971; 284: 878-81.
${ }^{3}$ Lenz W, Knapp K. Thalidomide embryopathy. Arch Env Health 1962; 5: 100-5.

${ }^{4}$ Naus $J$. The distribution of the size of the maximum cluster of points on a line. J Am Stat Assoc 1965; 60: 532-8.

${ }^{5}$ Naus J. Some probabilities, expectations and variances for the size of smallest intervals and largest clusters. $J \mathbf{A m}$ Stat Assoc 1966; 61: 1191-9.

${ }^{6}$ Wallenstein S. A test for detecting clustering over time. Am J Epi 1980; 111: 367-72.

${ }^{7}$ Kline J. Personal communication.

${ }^{8}$ Oakley G. Birth Defects Branch, Centers for Disease Control, personal communication.

${ }^{9}$ Breslow NE, Day NE. The analysis of case control studies. Vol. 1 in Statistical Methods in Cancer Research, Lyon: International Agency for Research on Cancer. 1980.

${ }^{10}$ Mantel N, Haenzel W. Statistical aspects of the analysis data from the retrospective studies of a disease. Jnl Nat Cancer Inst 1959; 22: 719-48.

${ }^{11}$ Noonan JA, Nadas AS. The hypoplastic left heart syndrome. Pediatr Clin N. Amer 1958; 5: 1029-56.

${ }^{12}$ World Health Organisation: Manual of the international statistical classification of diseases, injuries, and causes of death. Vol. 1, Geneva: World Health Organisation, 1975.

${ }^{13}$ Nelson F. Bureau of Vital Statistics, New York City Health Department, personal communication.

${ }^{14}$ Spych P. New Jersey State Department of Health, personal communication.

${ }^{15}$ Bound JP, Logan WFWE. Incidence of congenital heart? disease in Blackpool 1957-1971. Br Heart J 1977; 39: 455-60.

${ }^{16}$ Esscher E, Michaelson M, Smedby B. Cardiovascular malformation in infant deaths. Ten year clinical and epidemiologic study. Br Heart J 1975; 37: 824-9.

${ }^{17}$ Alberman ED, Fedrick JM, Schutt WH. Hypoplastic left heart complex. J Med Genet 1967; 4: 83-7.

${ }^{18}$ Snow J. On the mode of communication of cholera. Second edition much enlarged. London: Churchill, 1855.

${ }^{19}$ Fleiss JL. Statistical methods for rates and proportions, 2nd ed. New York; John Wiley, 1981: 126.

${ }^{20}$ Miettinen OS, Reiner ML, Nadas AS. Seasonal incidence of coarctation of the aorta. Br Heart J 1961; 23: 103-7.

${ }^{21}$ Elwood JM, Rogers JR. Seasonal occurrence of congenital abnormalities in Canada. Can J Pub Health 1977; 68: 233-6.

${ }^{22}$ Rothman KJ, Fyler DC. Seasonal ocurrence of complex ventricular septal defect. Lancet 1974; ii: 193-7.

${ }^{23}$ Paneth, Lansky M, Hiatt IM, Hegyi T. Congenital malformation clusters in Eastern United States. Lancet 1980; ii: 808-9.

${ }^{24}$ Warburton D, Kline J, Stein Z, Susser M. Trisomy cluster in New York. Lancet 1977; ii: 201.

${ }^{25}$ Pai GS, Valle D, Thomas G, Rosenbaum K. Cluster of trisomy-13 live births. Lancet 1978; i: 613.

${ }^{26}$ Barsel-Bowers G., Pueschel SM, Abuelo DN, Charley J. A cluster of infants born with trisomy 18. N Engl J Med 1980; 302: 120.

${ }^{27}$ Carey JC. Chromosomal disorders. In Rudolph ASM, ed. Pedatrics, 17th ed. Norwalk: Appleton-Century-Crofts $1982,246$.

${ }^{28}$ MMWR 1977; 26: 231.

${ }^{29}$ MMWR 1977; 26: 2 .

${ }^{30}$ MMWR 1977; 26: 32.

${ }^{31}$ Coffey VP, Jessop WJE. Maternal influenza and congenital deformities. A prospective study. Lancet 1959; ii: 935-8.

${ }^{32}$ Hardy J. The effect of Asian influenza on the outcome of pregnancy. Baltimore, 1957-1958. Amer J Pub Health 1961; 51: 1182-8. 